\title{
Doença de Behçet e Gestação: Relato de Caso e Revisão da Literatura ${ }^{(*)}$
}

\section{Behçet's Disease and Pregnancy: Case Report and Literature Review}

\author{
Venina Isabel Poço Viana Leme de Barros ${ }^{(1)}$, Paulo José Leme de Barros ${ }^{(2)}$, Elisa Teresinha Hacbarth ${ }^{(3)}$
}

\section{RESUMO}

A doença de Behçet (DB) é uma vasculite sistêmica com freqüente ocorrência de fenômenos trombóticos. Os autores relatam o caso de gestação de paciente com DB de difícil controle prévio e concomitante heterozigoze para o fator $\mathrm{V}$, com história prévia de múltiplas erisipelas nos membros inferiores e história familiar de tromboembolismo. A gestação evoluiu com remissão da DB e foi usado heparina fracionada profilática. Os autores discutem os envolvimentos de fatores trombofílicos na gestação de pacientes com DB.

Palavras-chave: doença de Behçet, trombofilias, gestação.

\section{INTRODUÇÃO}

A doença de Behçet (DB) é uma vasculite recidivante crônica que tem como manifestação clínica marcante a presença de úlceras orais e genitais. Manifestações de envolvimento vascular ocorrem em um terço dos pacientes, com predominância de trombose venosa nos membros inferiores. As tromboses arteriais, embora mais graves, são menos freqüentes na doença ${ }^{(1)}$.

O curso da doença durante a gestação não apresenta um padrão definido, o que impõe um seguimento pré-natal rigoroso, dado o alto risco para ocorrência de fenômenos trombóticos ${ }^{(2)}$.

Os autores relatam e discutem as condutas realizadas em paciente com DB de difícil controle previamente à gestação, mas que apresentou boa evolução clínica e resposta terapêutica com uso precoce de heparina fracionada.

\begin{abstract}
Behçet's disease (BD) is a systemic vasculitis in which thrombosis is a common clinical complication. We report a case of a pregnant woman with $B D$ and the presence of heterozigous factor $V$, previous erisipela lesions and family history of thromboembolisms. Her BD evolved to remission during gestation, nevertheless, low molecular weight heparin was maintaned during pregnancy. In this report, we discuss the thrombophilic aspects in pregnant women with $B D$.
\end{abstract}

Keywords: Behçet's disease, thrombophilias, pregnancy.

\section{RELATO DE CASO}

Paciente com 27 anos de idade, sexo feminino, branca, casada, advogada, descendente de libaneses, com diagnóstico de DB há quatro anos e portadora heterozigota de mutação do Fator V. Previamente à gestação, fazia uso de prednisona $5 \mathrm{mg} /$ dia durante cinco meses, azatioprina $100 \mathrm{mg} /$ dia durante um ano, desogestrel $75 \mathrm{mg} /$ dia e ácido fólico $5 \mathrm{mg} /$ dia. Relatava que no início do quadro apresentou lesões urticariformes por todo o corpo, além de úlceras orais e genitais. Relatava grande dificuldade de controle do quadro de dor articular e nas pernas. No início da doença recebeu quatro infusões endovenosas de ciclofosfamida. Relatava uso prévio de metotrexato, suspenso havia dois anos. Teve várias internações prévias por erisipelas, além de duas broncopneumonias e várias pielonefrites. Iniciou anticoncepcional de uso contínuo (desogestrel) há três anos, pois piorava das

* Trabalho realizado na Faculdade de Medicina da Universidade de São Paulo (FMUSP), São Paulo, SP, Brasil. Recebido em 07/03/2005. Aprovado, após revisão, em 27/04/2005.

1. Mestra e doutora em Medicina - Obstetrícia e Ginecologia - pela FMUSP. Médica Obstetra e Ginecologista no Hospital das Clínicas da FMUSP.

2. Mestre e doutor em Medicina - Reumatologia - pela FMUSP. Médico preceptor em Clínica Médica no Complexo Hospitalar do Mandaqui, São Paulo, SP, Brasil.

3. Mestra e doutora em Medicina - Reumatologia - pela Universidade Federal de São Paulo/Escola Paulista de Medicina (UNIFESP/EPM). Médica Chefe do Serviço de Reumatologia do Hospital Prof. Edmundo Vasconcelos, São Paulo, SP, Brasil.

Endereço para correspondência: Dra. Venina Viana de Barros. R. Leão XIII, 23, loja 4, Santana, CEP 02526-000. São Paulo, SP, Brasil. Tel. (1 1) 6256-7306; fax (1 1) 6356-7096; e-mail: vipvbar@ig.com.br 
úlceras genitais no período pré-menstrual. Apresentava episódios freqüentes de recidiva das úlceras genitais. Até sete meses atrás havia sido submetida a três infusões de infliximabe para controle da doença. Nessa ocasião, por sentir fortes dores nas articulações coxofemorais, realizou ressonância magnética nuclear, que mostrou necrose asséptica da cabeça do fêmur bilateral, mais intensa à esquerda. Foi submetida à cirurgia ortopédica para descompressão acetabular no fêmur esquerdo seis meses antes da gestação, porém não obteve sucesso na melhora da dor. Previamente à gestação, apresentava FAN, anticardiolipina IgM e IgG, anticoagulante lúpico e autoanticorpos antitiróides negativos. Nos antecedentes familiares relatava que a mãe havia apresentado "reumatismo" na infầncia e posterior tromboembolismo pulmonar. Um dos irmãos já havia apresentado trombose venosa profunda de membro inferior. O pai apresentava diabetes. A gestação foi planejada e após 40 dias sem anticoncepção, a ultra-sonografia transvaginal revelou gestação tópica e única. Foi suspenso o uso de azatioprina com cinco semanas de gestação; a prednisona foi suspensa pela própria paciente com seis semanas. Foi introduzido heparina não fracionada 5000 UI 12/12 horas, após seis semanas de gestação e aumentada a dose para 10 mil UI 12/12 horas, a partir da $25^{\mathrm{a}}$ semana de gestação. Fez suplementação com carbonato de cálcio $500 \mathrm{mg}$ associado à vitamina $\mathrm{D}$, desde o início do uso da heparina, bem como orientação dietética de ingestão de $1,5 \mathrm{~g} /$ dia de cálcio. Evoluiu com total remissão da doença durante a gestação. Apresentou episódio de infecção urinária com 36 semanas de idade gestacional. Evolui para trabalho de parto prematuro, apesar do uso de cefalexina parenteral e uterolítico endovenoso. Submetida a parto cesariano por dificuldade de abdução dos membros inferiores em razão da presença de necrose asséptica da cabeça do fêmur bilateral. O recém-nascido (RN), do sexo masculino, com peso de nascimento de 2.690g, teve índice de Apgar de 9 e 10 (no primeiro e quinto minutos de vida, respectivamente). O RN apresentou taquipnéia transitória, necessitando de oxigênio por 12 horas. Teve alta no quarto dia de vida.

No primeiro dia pós-cesariana foi reintroduzida a prednisona $5 \mathrm{mg} / \mathrm{dia}$. A paciente apresentou herpes no pavilhão auricular direito no primeiro pós-operatório, sendo tratada com aciclovir local com rápida melhora. Foi medicada com enoxaparina $40 \mathrm{mg} /$ dia nos quatro primeiros dias de pósoperatório e recebeu alta com varfarina sódica $5 \mathrm{mg}$ /dia por 40 dias.

\section{DISCUSSÃO}

A síndrome de Behçet foi descrita em 1937 pelo turco Hulusi Behçet como uma tríade clássica de úlceras orais e genitais, acompanhadas de alterações inflamatórias oculares e musculoesqueléticas ${ }^{(3)}$. Relatos de casos semelhantes, porém, já haviam sido descritos por Hipócrates no século $\mathrm{V}$ antes de Cristo e citados pelo grego Adamantiades em $1931^{(3)}$. Outras características clínicas incluem manifestações cutâneas, neurológicas, vasculares, gastrointestinais e articulares. Em razão de sua forma clínica de manifestação, era até recentemente considerada uma espondiloartropatia soronegativa. Com o melhor entendimento de sua fisiopatologia, a DB é hoje vista como uma vasculite sistêmica. $\mathrm{O}$ acometimento primário da doença consiste em uma heterogeneidade de envolvimento vascular. Infiltrado perivascular de células mononucleares sem acometimento da própria parede vascular é visto em vários sítios vasculares, predominantemente nos vasos de pequenos calibres. $\mathrm{O}$ envolvimento de vasos de grandes calibres ocorre em um quarto a um terço dos pacientes ${ }^{(1)}$. Nestes, a manifestação clínica pode ser um quadro de trombose secundária ao processo inflamatório envolvendo o vaso acometido ${ }^{(1)}$.

O aparecimento da doença na terceira década de vida é comum, mas pode ocorrer em qualquer idade. Apresenta uma incidência de 80-300/100.000 pessoas na Turquia, de 13,6/ 100.000 no Japão e de 0,13/100.000 nos Estados Unidos. A incidência é um pouco maior em mulheres (1,5-5:1) em certos países mediterrâneos e no Meio-Leste Europeu ${ }^{(3)}$.

Embora a DB seja diagnosticada em pacientes em idade reprodutiva, pouco se sabe sobre a influência da gestação no curso da DB. Uzum et al. ${ }^{(4)}$ estudaram 44 gestações em 28 pacientes com DB na Turquia, classificadas segundo os critérios do International Study Group for Behçet's disease. Houve remissão da doença em 23 gestações (52,3\%), exacerbação durante a gestação em 12 (27,3\%). A doença manteve-se inalterada em nove gestações $(20,4 \%)$. A manifestação clínica mais freqüente quando da ativação da doença foi o aumento na intensidade e gravidade das úlceras orais na gestação. Manifestações de úlceras genitais, inflamações oculares e artrite formam outros sinais de exacerbação. Ocorreram três abortos nessa casuística e nenhuma outra complicação fetal. A influência da gestação no curso clínico da DB foi muito variável, mesmo durante diferentes gestações na mesma paciente. Os autores especulam que a gestação não influencia no curso natural da $\mathrm{DB}^{(4)}$.

Uma "síndrome de Behçet transitória" tem sido relatada nos RNs de mães com DB ${ }^{(5)}$. Essa síndrome é caracterizada 
por crescimento intra-uterino restrito e lesões mucocutâneas neonatais transitórias. Jog et al. ${ }^{(5)}$ relatam caso de RN de mãe com DB que evoluiu com convulsões generalizadas no sexto dia de vida, com achado ultra-sonográfico de áreas de hemorragia ao redor de áreas isquêmicas. Este RN evoluiu para óbito no nono dia de vida. Os autores levantam a hipótese de uma manifestação neurológica da DB como causa etiológica neste caso.

No presente caso, a paciente apresentava uma DB de difícil controle antes da gestação. Cursou com total remissão da doença durante a gestação. A heparinização profilática foi instituída desde início da gestação, em razão do alto risco de trombose que a paciente apresentava pela associação de patologias: DB, múltiplas erisipelas anteriores, heterozigota para Fator $\mathrm{V}$ e forte antecedente familiar de fenômenos tromboembólicos.

Lesões inflamatórias venosas são anormalidades freqüentes na DB, e usualmente resultam em tromboses venosas superficiais ou profundas e recorrentes ${ }^{(1)}$. Os mecanismos aventados relacionados com os eventos trombóticos venosos seriam: disfunção endotelial, hipofibrinólise, hipercoagulabilidade plasmática e aumento dos eucosanóides ${ }^{(2)}$.

$\mathrm{O}$ aumento profilático da dose da heparina fracionada na segunda metade da gestação foi realizado em decorrência do fenômeno fisiológico do aumento dos fatores da coagulação que ocorre nessa fase $\mathrm{e}^{(6)}$. Em razão do alto risco de trombose no puerpério, a anticoagulação foi mantida

\section{REFERÊNCIAS}

1. Calamia KT, Schirmer M, Melkoglu M: Major Vessel Involvement in Behçet Disease. Curr Opin Rheumatol 17: 1-8, 2004.

2. Vaya A, Forner MJ, Estelles A, et al: Intracardiac thrombosis in a case of Behcet's disease associated with the prothrombin 20210G-A mutation. Haematologica 85: 425-8, 2000.

3. Kontogiannis V, Powell RJ: Beh inverted question market's disease Postgrad Med J 76: 629-37, 2000.

4. Uzum S, Alpsoy E, Durdu M, Akman A: The clinical course of Behçet's disease in pregnancy: a retrospective analysis and review of the literature. J Dermatol 30: 499-502, 2003. durante os 40 dias de pós-parto. As pacientes com quadro de vasculite, e particularmente aquelas com forte história familiar de trombose, devem também ser investigadas para as trombofilias conhecidas. A associação de conhecidas trombofilias com a DB já foi relatada como importante fator predisponente de tromboses, quer sejam: deficiência de proteína $\mathrm{C}$ e $\mathrm{S}$, gene mutante para protrombina e presença de Fator $\mathrm{V}^{(2,7-9)}$. A anticoagulação na gestação, quando se faz necessária nesses casos, é segura para mãe e feto, e previne muitas complicações. Postula-se que no caso da DB, a anticoagulação melhoraria até mesmo o curso da doença ${ }^{(1)}$. Em revisão de literatura sobre os diversos acometimentos vasculares da DB, Calamia et al. deixam claro a necessidade de anticoagulação precoce com uso de heparina nas manifestações vasculares, principalmente quando há outros concomitantes predisponentes a tromboses ${ }^{(1)}$.

Os autores relataram e discutiram o caso de uma paciente que apresentava uma DB de dificil controle, que apresentou remissão do quadro durante gestação. Como havia associação de doenças predisponentes para eventos tromboembólicos (como a presença heterozigótica do fator $\mathrm{V}$, história pessoal de erisipelas anteriores e história familiar de tromboses), optou-se pelo uso precoce e progressivo de heparina fracionada. O seguimento e o tratamento referidos culminaram no sucesso do resultado da gestação, em que a mãe e a criança obtiveram boa evolução final.

5. Jog S, Patole S, Koh G, Whitehall J: Unusual presentation of neonatal Behçet's disease. Am J Perinatol 18: 287-92, 2001.

6. Robertson L, Greer I: Thromboembolism in Pregnancy. Curr Opin Obstet Gynecol 17: 113-6, 2005.

7. Chafa O, Fisher AM, Meriane F, et al: Behçet's syndrome associated with protein S deficiency. Thomb Haemost 67: 1-3, 1992.

8. Shehto NM, Ghosh K, Abdul Kader B, Assad HS: Extensive venous thrombosis in a case of Behçet disease associated with heterozygous protein C deficiency. Thromb Haemost 67: 283, 1992.

9. Ghermazi S, Hamza M, Dellagi K: Protein S deficiency and antibodies to protein S in patients with Behçet's disease. Thromb Res 86: $197-$ 204, 1997. 